\title{
Stage 0 Skin Cancer
}

National Cancer Institute

\section{Source}

National Cancer Institute. Stage O Skin Cancer. NCI Thesaurus. Code C3640.

Stage 0 includes: T is, NO, MO. T is: Carcinoma in situ. N0: No regional lymph node metastasis. M0: No clinical or radiog raphic evidence of distant metastasis. (AJCC 6th and 7th eds.) 